\title{
The Machinability of MAR-M247 Superalloy
}

\section{Shao-Hsien Chen ${ }^{\mathrm{a}}$, Sen-Chieh Su ${ }^{\mathrm{b}}$, Po-Chun Chang ${ }^{\mathrm{c}}$, Shuo-Yan Chou ${ }^{\mathrm{c}}$, and Kong- King Shieh ${ }^{d}$}

\author{
a. Department of Mechanical Engineering, National Chin-Yi University of Technology, No.35, \\ Lane215, Sec.1, Chung-Shan Rd., Taiping City, Taichung, Taiwan, Republic of China \\ b. Department of Mechanical Engineering, National Chung Cheng University, Chia-Yi, Taiwan 621, \\ R.O.C. \\ c. Department of Industrial Management, National Taiwan University of Science and Technology, 43, \\ Sec.4, Keelung Rd., Taipei, Taiwan, R.O.C. \\ d. Department of Industrial Management, Oriental Institute of Technology, \\ \#58, Sec.2, Sihchuan Rd., Banciao City, Taipei County, Taiwan, R.O.C.
}

corresponding author: e6036@ncut.edu.tw

\section{Keywords: Nickel-base Superalloy, Mar-M247}

\begin{abstract}
Nickel-base superalloy is a special super heat resistant alloy developed by U.S in 1970s. It is mainly applied to turbine parts as well as high-temperature components. Nickel-base superalloys exhibit an excellent high strength, low thermal conductivity and creep resistance as well as work hardening. It is the most difficult to be machined with high-speed cutting among different sorts of high-temperature superalloys and is a material presenting multifold challenges for machining. The purpose of this study aims at the machinability of Nickel-base alloys. Engineering statistical analysis was employed to observe the cutting speeds, feed rates and surface roughness at first place. The researcher further applied the half-normal probability plot (HNPP), Pareto analysis and ANOVA to identify the cross effects and probed into the characteristics of Nibase alloy.
\end{abstract}

\section{Introduction}

Nickel-base superalloys are widely used in aerospace field. The development of aerospace industry is thriving globally, including in the extent of civil aerospace, military purpose, satellites and rocket telemetry etc. Since Nibase alloys demonstrate high strength, low thermal conductivity, creep resistance and work hardening, these features has led the material difficult to be machined. However, it still retains superior mechanical properties, resistance to fatigue and high-temperature corrosion resistance under elevated temperatures. Therefore, it is extensively used in the parts required high-temperature resistance, such as aerocrafts' turbines, nuclear power plants' turbine parts. It is deemed that the Nibase alloys have the best high-temperature mechanical properties comparing with other materials [1].

Nickel base alloy is a distinctive super high-temperature alloy which was successfully introduced in the 1970s. Under an highly elevated temperature, it would still retain excellent mechanical properties, such as tensile strength, fatigue resistance and creep strength etc [2][3]. On this basis, it also becomes problematic to machine Nickel base alloy. Mar-M247 material is a surpassing superalloy with super heat resistance and corrosion resistance. In spite of the stated benefits, it has low thermal conductivity and thermal expansion [4], so it is categorized into difficult-to-cut materials.

The characteristics make Nickel base superalloy difficult to cut are:

a. High hardness, b. High strength under elevated temperature, c. High degree of work hardening

d. High strength of the material, e. Low thermal conductivity, f. High tendency of BUE (Built-up edge)

\section{Analysis and introduction of theories}

\subsection{Strengthening mechanism of Nickel base superalloy}

The strengthening mechanism of difficult-to-cut materials possesses a good strength and ductility in both medium and low temperature. Its main strengthening mechanisms are as following: 


\subsubsection{Solid solubility strengthening of Austenite matrix}

The alloy contents $19 \%$ of $\mathrm{Cr}$ and 3\% of $\mathrm{Mo}$, and the atoms of $\mathrm{Cr}$ and $\mathrm{Mo}$ are larger than Ni. For this reason, the material would become substitutional solid solution in solid-solution matrix and the matrix grids would thus twisted and cause strain, as demonstrated in Fig. 1, in order to achieve the strengthening. But AISI4340 would not have high tendency of strain hardening.

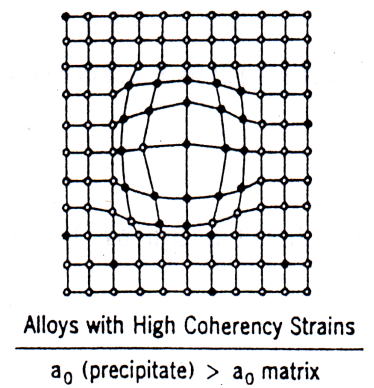

\subsubsection{Precipitate strengthening of $\gamma^{\prime \prime}$ and $\gamma^{\prime}$}

Fig. 1 Coherency strains by precipitates and matrix

Both $\gamma^{\prime \prime}$ and $\gamma^{\prime}$ are ordered and coherent precipitates. The strengthening sources to such precipitates are suggested generally as followings:

1. When the precipitates are arose from dislocations, the anti-phase boundary and fault hardening have emerged therefrom., 2. When dislocations go over the precipitates, the strength of the precipitates would be. , 3. The coherency strain as shown in Fig. 1. , 4. In the case that the size of precipitates is large enough, dislocations would have climbing on or bypassing the precipitates and form dislocation loops. , 5. The size of precipitates. , 6. The volume percent of precipitates

\subsection{The machinability of Nickel base superalloy}

Generally speaking, multifarious variable factors would act upon a material's machinability. With respect to milling, it could be sorted to several cases. Yet in the modern cutting history, the main reasons why Nibase superalloys are always classified in difficult-to-cut materials is considered as following statement:

The strengthening mechanism of Nibase superalloy relies on coherent precipitation hardening effect of $\gamma$ 'phase ( $\gamma$ and $\gamma$ 'phases are both FCC, whose mechanical properties own good ductility. The discrepancy of its lattice constant is merely about $1 \%$. )to make the alloy to reach a high mechanical strength under elevated temperature. At the degree of $650^{\circ} \mathrm{C}, \gamma^{\prime}$ and $\gamma^{\prime \prime}$ precipitation hardening's coherency with the matrix was working well [6] On this ground, it still possessed an exceedingly high level of flow stress with a higher degree of plastic deformation. In the milling process, the shearing location would come up with extremely high strain rate $\left(\gamma \doteqdot 10^{5}\right)$ and large plastic deformation $(\gamma=2 \sim 5)$. The Nibase superalloy's structure consists of considerable alloy elements and precipitates. In the case of excessive plastic deformation occurred, high stacking fault would appear, and it would induce an extraordinarily high flow shear stress. Stacking faults are structured with three fundamental forms:

1. Superlattics Intrinsic (or extrinsic) Stacking Faults (SISF, SESF), 2. Antiphase Boundary Faults (APB) , 3. Complex Faults (CF)[7] [8][3][9]

\section{Experimental}

Three fundamental principles constituted the experiment plan [13][14]: replicating, randomizing and blocking. "Replicating" was to minimize the errors in the experiment. "Randomize" was to avoid the effects from changing in the results and experiment location. By randomization, the random numbers would effectively offset the interferences from external factors. Blocking on the various factors is to improve the comparative accuracy and should be applied to reducing or eliminating travel variation of interference factors. The discussion on the experiments would be divided into two stages. The first stage was screening experiment. The main purpose was to discover the significant factors. The numbers of experiments and resolutions should be judged and then the experiment analysis was carried out. The second stage was to optimize the experiment. It was aiming at optimizing and finding the optimal value. The results from the screening experiment were applied to acquiring the regression equation and obtaining the optimal value by Central Composite Design. 


\subsection{Screening experiment}

The screening experiment was split into three steps as the following description.

\subsubsection{Selection from experiment plans}

There were to approaches to sort out the significant factors by screening experiment. One was the full factorial experiment and the others were fractional factorial experiments. The full factorial experiment allows obtaining which factor was significant or the significancy of interactions between factors. Due to huge amount of trials required for the full factorial experiments, there was not enough time and energy for this experiment, but fractional factorial experiment would need some more trials and evidences in order to run it. The experiment model would be based on the purpose of the experiment, objective conditions, variable factors and criteria selection. This experiment has employed the half fractional factorial design.

\subsubsection{Data analysis}

The data analysis employed the analysis of variance (ANOVA) and relevant methods to run the experiments, such as test coefficient R2, testing F- and t-value, and hypothesis testing.

\subsubsection{Analysis of variance (ANOVA)}

Under the same level of significance " $\alpha$ ", the method to test whether k-number of population mean was equal is "analysis of variance". Table 1 is about the analysis of variance [15].

Process of ANOVA

1. The total variation was partitioned into experimental factor variation and error variation.

2. To determine the degree of freedom of each corresponding variation.

3 . Sum of squares of variation divided by the degree of freedom to convert to variance.

4. To acquire $F$ test statistic

5. In case of $F>F \alpha(v R, v E)$, it means $R$ factor's effect to response value is significant. If $F<F \alpha(v R$

, $v \mathrm{E}), \mathrm{R}$ factor's effect to response value is insignificant.

\subsubsection{Testing coefficient $R 2$}

$$
\mathrm{R}^{2}=\frac{\mathrm{SS}_{\mathrm{R}}}{\mathrm{SS}_{\mathrm{T}}}
$$

$\mathrm{SS}_{\mathrm{R}}$ is regression sum of square, also known as between-population variance

$$
S S_{R}=\sum_{\mathrm{i}=1}^{\mathrm{k}} \sum_{\mathrm{j}=1}^{\mathrm{n}_{\mathrm{i}}}\left(\mathrm{y}_{\mathrm{i}}-\overline{\mathrm{y}}_{\ldots} \ldots\right)^{2}=\sum_{\mathrm{j}=1}^{\mathrm{n}_{\mathrm{i}}}\left(\mathrm{y}_{\mathrm{i}}-\overline{\mathrm{y}}_{\ldots} \ldots\right)^{2}
$$

$\mathrm{SS}_{\mathrm{T}}$ is total sum of square, also known as total variation.

$$
\mathrm{SS}_{\mathrm{T}}=\sum_{\mathrm{i}=1}^{\mathrm{k}} \sum_{\mathrm{j}=1}^{\mathrm{n}_{\mathrm{i}}}\left(\mathrm{y}_{\mathrm{ij}}-\overline{\mathrm{y}}_{\ldots}\right)^{2}
$$

$\mathrm{SST}=\mathrm{SSR}+\mathrm{SSE}, \mathrm{SS}_{\mathrm{E}}$ is residual sum of square, also known as within-population variation.

$$
\mathrm{SS}_{\mathrm{E}}=\sum_{\mathrm{i}=1}^{\mathrm{k}}\left[\sum_{\mathrm{j}=1}^{\mathrm{n}_{\mathrm{i}}}\left(\mathrm{y}_{\mathrm{ij}}-\overline{\mathrm{y}}_{\ldots} \ldots\right)^{2}\right]
$$

$\mathrm{R}^{2}$ value is the ratio of between-population variation to total experimental variation value, which is the ratio that total variation of experimental data could describe.

\subsubsection{F-test and t-test}

Whether the regression coefficient of experimental factors is significant could be proved by testing F-value or t-value. $\mathrm{MS}_{\mathrm{E}}$ is residual sum of squares, and $\mathrm{MS}_{\mathrm{R}}$ is the mean sum of squares.

$$
\begin{aligned}
& \mathrm{F}=\frac{\mathrm{MS}_{\mathrm{R}}}{\mathrm{MS}_{\mathrm{E}}} \\
& \mathrm{t}^{2}=\mathrm{F}
\end{aligned}
$$

\subsubsection{Experiment analysis}

The purpose was to obtain the regression equation. The lack-of-fit test and residual test were to assure if the regression equation was appropriate. The process of analyzing was set to four steps:[15]

1. To construct a regression mode1,2. To test the regression mode1,3. To diagnose the regression model

4. To analyze and assess the regression model, 


\subsection{Optimizing the experiment analysis}

The Table 3 is about fitting two-stage regression model and lack-of-fit test. All the factors' combinations and fitting two-stage regression are as following:

$\mathrm{Y}=\beta_{0}+\beta_{1} \mathrm{~A}+\beta_{2} \mathrm{~B}+\beta_{3} \mathrm{C}+\beta_{4} \mathrm{~A}^{2}+\beta_{5} \mathrm{~B}^{2}+\beta_{6} \mathrm{C}^{2}$

$A=$ cutting speed (factor $A$ )

$\mathrm{B}=$ feed rate (factor $\mathrm{B})$

$\mathrm{C}=$ depth of cut (factor $\mathrm{C}$ )

Implementing two-stage-model lack-of-fit test:

$$
\begin{aligned}
& H_{0}: \quad y=\beta_{0}+\beta_{1} A+\beta_{2} B+\beta_{3} C+\beta_{4} A^{2}+\beta_{5} B^{2}+\beta_{6} C^{2} \\
& H_{1}: \quad y \neq \beta_{0}+\beta_{1} A+\beta_{2} B+\beta_{3} C+\beta_{4} A^{2}+\beta_{5} B^{2}+\beta_{6} C^{2}
\end{aligned}
$$

Building the regression model to implement residual analysis has proved the appropriateness of regression model. In Fig. 7, the residual analysis graph demonstrated the tendency of changing.

By the interaction between significant factors and quadratic term, a contour map and 3D response surface of ball screw's surface roughness are as illustrated in Fig. 8 and Fig. 9.

Regression equation:

$\mathrm{y}=0.673393-0.00239380 \mathrm{~A}+3.08231 \mathrm{~B}-1.51041 \mathrm{C}+2.60767 \mathrm{E}^{-5} \quad \mathrm{~A}^{2}-61.0850 \mathrm{~B}^{2}+1.12598 \mathrm{C}^{2}$

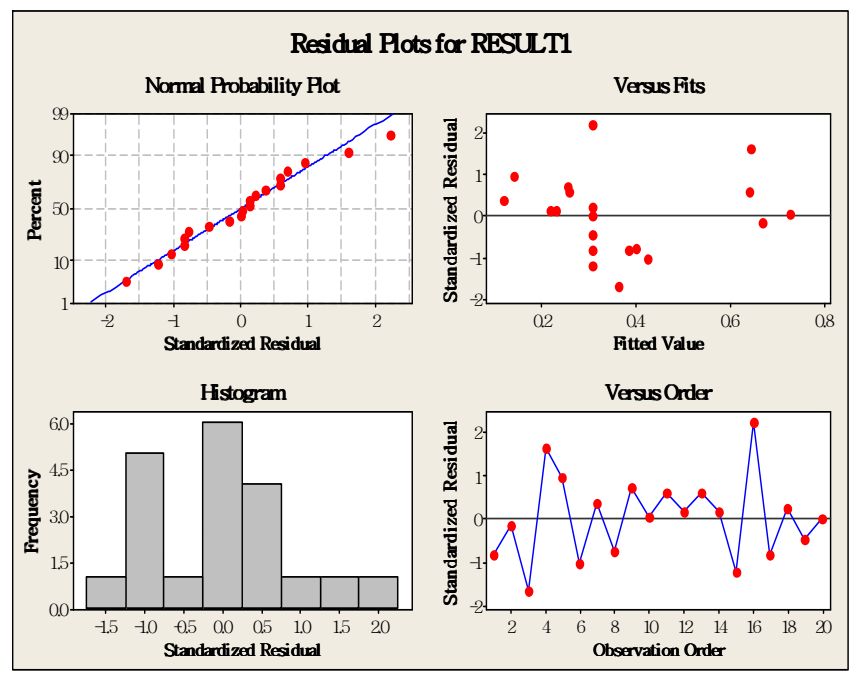

Fig.7 The residual analysis graph

Surface Plot of Result vs B, A

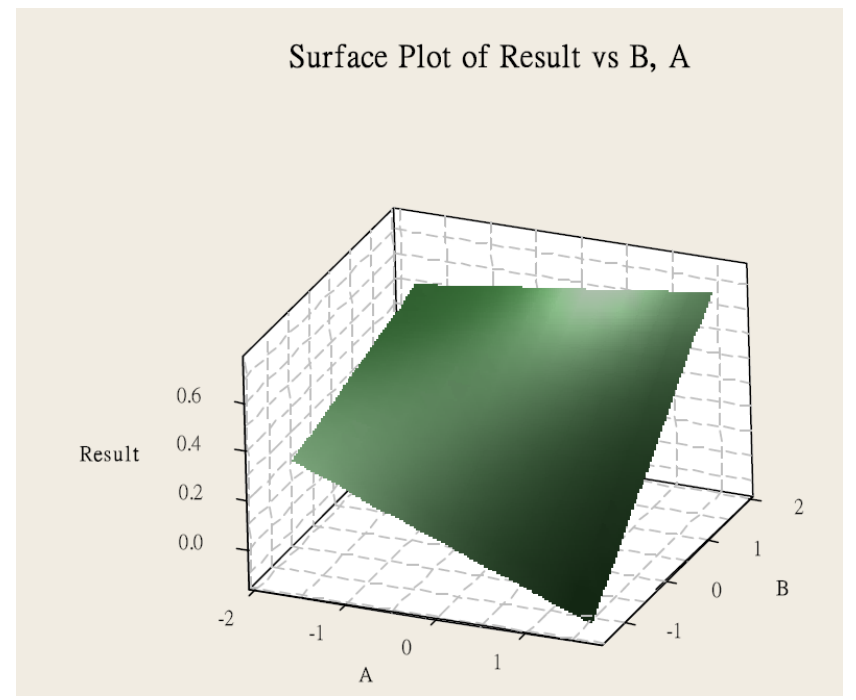

Fig. 9 Surface Plot of Result

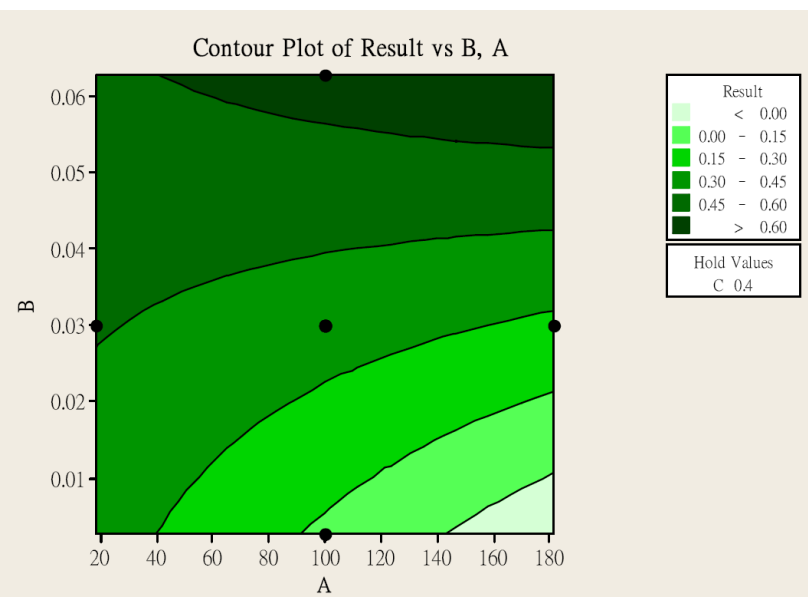

Fig. 8 Contour plot of Result

\section{Results and discussion}

A contour map was generated by Minitab., which is about the effects to surface roughness from cutting speed and feed rate. By the illustration from Fig. 9, the researcher was able to know that how to reduce the degree of surface roughness required a fast cutting speed and slow feed rate in order to reach highly precise milling, but 
the working efficiency would degrade. Therefore, a proper milling-condition combination must be employed in order to meet the requirement of high-accuracy milling. As exhibited in Fig. 4, the " $\square$ " is significant main effect. The significant factor deviating from other point implies the significant variation.

\section{Conclusion}

Under a high-temperature machining process, Nibase alloys are very likely to have work hardening. The material is very difficult to cut as well as machine. If the temperature goes over the material-softening critical point, it would beneficial for milling; however, the over-elevated temperature would induce the cutting tool softened, and thus the tool would not be preferable to milling. In addition, the cutting speed for carbide cutting tools should not be too fast. If the cutting speed is to be increased, the depth of cut or feed rate should be reduced. Therefore, "temperature" is definitely an essential issue for milling the Nibase alloy. This experiment applied data to build up an empirical formula of surface roughness. The machining process would be able to select an appropriate combination through the formula without affecting the work removal rate in order to meet the requirements for surface roughness.

\section{Reference}

[1]. Sims,Stoloff.Hagel,”SUPERALLOY II ”,Wiley-Interscience Publication,1987

[2].Wright,P.K.,and Chow,JG.,"Deformation characteristic of nickel alloys during machining," ASME, Jounal of Engineering for Industry,Vol.104,pp.85-93,1982。

[3]. Komanduri,R. and Schroeder,T.F,"On Shear Instability In Machining a Nickel Iron Based Superalloys ",Trans of The ASME ,Journal Of Engineering For Industry,Vol.108,1986。

[4]. Boyer,M.E. , and Gall ,T.L. ,Metals Handbook ASM, Desk Edition, 1985 。

[5]. M.C. Shaw, "Metal Cutting Principal", Clarendon, Oxford,1997

[6]. Foster,S.R.,Aucote,J., " Performance Sialon Cutting Tools When Machining Nickel Base Aerospace",Materials Science and Technology ,No.2,1986,pp.700-708

[7] J.Lorentzon,N. Jorvstrat," Modeling tool wear in cemented-carbide Machining alloy 718, Int. J. Machine Tool and Manufacture, Vol.48,1072-1080, 2008

[8].Rahman,M., Seah, W.K.H, and Teo, T. T., "Machinability Of Inconel-718",Journal Of MaterialProcessingTechnology63,1997

[9].M.Alauddin,M.A.El Baradie and M.S.J Hashmi,"End-milling Machinability Of Inconel 718",Journal of Engineering Manufacture,Vol210,1996,pp11-22。

[10]. Wang Jyh-Haur , "Study of High Speed End Milling of Inconel 718 Alloys " , National Taiwan University Department of Mechanical Engineering,1997.6

[11]. Y. S. Liao, H.M. Lin, J. H. Wang,"Behaviors of end milling Inconel 718 superalloy by cemented carbide tools ", Journal Of Material Processing Technology,Vol.201,pp460 465,200

[12]. Pawade RS, Joshi SS, Brahmankar PK," Effect of machining parameters and cutting edge geometry on surfaceintegrity of high-speed turned Inconel 718”. Int J Mach Tools Manuf,Vol 48,PP15-28,2008

[13]. David W. Stewart, Prem N. Shamdasani, Focus Groups: Theory and Parctice, 2002

[14]. D.C.Montgomery, Design and Analysis of Experiment, 5th, New York, 2001

[15].Lee C-S,"The variance analysis of artwork dimensional change characteristics for PCB", National Pingtung University of Science and Technology,2003

[16].Hsu Yeh-Chi,"Research of precision machining characteristics in plastic aspheric lens", National Chung Hsing University Department of Mechanical Engineering ,2006

[17]. Lin Chao-Yuan,"The Design of an Adjustable Preload System and Structure Analysis for High Speed Spindles",National Taiwan University of Science and Technology,2001

[18].Lai Ting-Hsuan,"Using Experimental Design to Improve Seasonings of Snack Food",National Cheng Kung University,2002

[19]. A.I.Khuri and J.A.Cornell , Response Surface Design and Analysis, New York , 1987

[20].R.H.Myers and D.C.Montgomery , Response SurfaceDesign Methodology :Process and Produc Optimizat ion Using Designed Experiments , New York, 1995

[21].Yu-Tao Hsiao,A Study on the Optimum Assembly Parameters of the Single-Axis Table Positioning, National Chung Hsing University Department of Mechanical Engineering,2008 •

[22]. Y.C. Tsai - J.M. Hsieh,"An analysis of cutting-edge curves and machining performance in the Inconel 718 machining process", Int J Adv Manuf Technol, Vol.25:PP.248-261,2005

[23].Shue-Liang Lin,"The Influence of Different Coated Tools when Milling MAR-M247”, National Chung Cheng University ,2000 